EPiC Series in Engineering
Volume 3, 2018, Pages 495-503
HIC 2018. 13th International
Conference on Hydroinformatics

\title{
Hydrological Modelling of the Cascina Scala catchment
}

\author{
Enrico Creaco $^{1 *}$, Sara Todeschini ${ }^{1 \dagger}$ and Marco Franchini2 ${ }^{\ddagger}$ \\ ${ }^{1}$ University of Pavia, Dipartimento di Ingegneria Civile ed Architettura, Via Ferrata 3, 27100 \\ Pavia, Italy \\ ${ }^{2}$ Università degli Studi di Ferrara, Dipartimento di Ingegneria, Via Saragat 1, 44100 Ferrara, Italy \\ creaco@unipv.it, sara.todeschini@unipv.it, \\ marco.franchini@unife.it
}

\begin{abstract}
This paper presents results about the hydrological modelling of the Cascina Scala catchment. Following a preliminary analysis that proved the Nash cascade of reservoirs superior to the Clark model in the event-based rainfall-runoff simulation for this catchment, a new analysis was carried out to compare two different parameterization approaches applicable in gauged rain events. The former is based on estimating the optimal set of model parameters in each gauged event and then obtaining the ultimate set by averaging the values obtained over the whole group of events; the latter is based on estimating the optimal set of parameters directly on the whole group of gauged events. The results of the analysis proved the better performance of the latter, which enables better representation of the hydrological response of the catchment, evaluated in terms of water discharge pattern at the outlet.
\end{abstract}

\section{Introduction}

Rainfall-Runoff (RR) models, which enable reconstructing the water discharge hydrograph at catchment outlets or at the end of river reaches starting from the rainfall hyetograph, play a key role in Hydrology [ (Nash, 1957) (Box \& Jenkins, 1970) (Valencia \& Schaake, 1973) (Panu \& Unny, 1980) (Todini, 1988) (Kim, 2000) (Özger, 2009) (Londhe \& Charhate, 2010) (Alvisi, Creaco, \& Franchini, 2012) (Nayak, Venkatesh, \& Krishna, 2013) (Salas, Tarawneh, \& Biondi, 2012) (Rezaie-Balf \& Kisi, 2017)]. They are useful for many water-related problems, such as water resources management, urban drainage planning, and flood forecasting. To date, many methods and approaches have been introduced to model RR. These models can be categorized into continuous and event-based models

\footnotetext{
${ }^{*}$ He did the calculations and wrote the paper

${ }^{\dagger}$ She provided the data used for the modelling and helped in calculations and manuscript draft

${ }^{\star}$ He supervised the whole work
} 
(Ford \& Hamilton, 1996). Continuous models represent the RR transformation on a continuous-time basis, thus reproducing the water discharge at the catchment outlet also in the periods of no-rainfall [ (Dawdy \& O’Donnel, 1965) (Kim, 2000) (Alvisi, Creaco, \& Franchini, 2012) (Rezaie-Balf \& Kisi, 2017)]. Event-based models, instead, reproduce the RR transformation in single rainfall events [ (Nash, 1957) (Boufadel, 1998) (Feldman, 2000) (Roy-Poirier, Filion, \& Champagne, 2015)]. Another classification [ (Dooge, 1977) (Singh, 1995)] concerns the nature of the basic algorithms of the hydrological models. In fact, these models can be subdivided into physically based models, conceptual models, which in turn may contain various levels of physical information (Todini, 1988), and black-box models.

Conceptual models incorporate physical elements with simplified form (channels and storages), each of which is used to represent a significant or dominant constituent hydrologic process of the RR transformation (Chow, Maidment, \& Mays, 1988). When both rainfall and runoff data are available, the parameters of the conceptual (continuous and/or event-based) models can be directly estimated with the objective to obtain the best fit of the model. By taking account of the physics of the system, these models have potential for evaluating land use impact on hydrological processes, based on the relationships between model parameters and measurable physical characteristics [ (Chen \& Adams, 2006) (Todeschini, 2016)]. However, the parameterization methodology is crucial for the effectiveness of hydrological modelling. In fact, an effective parameterization must be able to attenuate the effects of noises present in rainfall and runoff time series. In this paper, two different parameterization approaches are compared in the hydrological modelling of an urban catchment. In the following sections, first the catchment and experimental data are presented, followed by the description of the hydrological modelling and by its application.

\section{Cascina Scala Catchment}

The Cascina Scala catchment (Figure 1), situated in the northern outskirts of Pavia, Italy, was considered in this work. This catchment was the site of a long experimental campaign between 1987 and 2006 (Papiri, Ciaponi, \& Todeschini, 2008). It is hydrologically isolated from the surrounding territory due to the presence of flat rural lands equipped with their own network of drainage channels.

The destination of the catchment is mainly residential, with an oscillating population around 1,500 inhabitants. Up to year 2001, the total surface added up to 14.37 ha, with 3.02 ha of pervious surfaces disconnected from the sewer networks. Therefore, the total contributing area was of about 11.35 ha.

The sewer system is equipped with 42 underground channels with circular or egg-shaped cross section. The outlet channel (see its location in Figure 1), which connects the Cascina Scala sewer system to the main line, has an egg-shaped $70 \mathrm{~cm} \times 105 \mathrm{~cm}$ cross section.

During the experimental campaign, rainfall intensity and water level measurements were carried out using a rain gauge ( $\pm 2 \%$ precision and $0.2 \mathrm{~mm}$ resolution) and an ultrasonic water level sensor ( $\pm 2 \%$ precision), respectively. These devices were installed on the roof of a barycentric building and inside the outlet channel, respectively. The use of a suitable rating curve enabled conversion from water level to water discharge at the outlet.

The measurement instruments described above enabled monitoring hyetographs and hydrographs with a time step of $60 \mathrm{sec}$ in numerous rain events from year 1986 to year 2001. The hydrographs were then reduced by the dry weather water discharge, thus producing the net/direct hydrographs.

For the calculations of this work, 32 rain events with available data concerning both rainfall and water discharge at the outlet were selected from the whole available data. The selection of the generic event was made based on the following criteria:

- smooth operation of the rain gauge and of the water level sensor; 
- total rainfall depth and maximum rainfall intensity larger than $5 \mathrm{~mm}$ and $6 \mathrm{~mm} / \mathrm{hr}$, respectively, in order to reduce measurement errors;

- rainfall homogeneity in the catchment, which was assessed by comparing the measurements at the barycentric benchmark rain gauge with those of an auxiliary rain gauge installed close to the outlet.

Table 1 reports the key features of 32 rain events in terms of total rainfall volume $h_{t o t}(\mathrm{~mm})$, water loss volume $h_{\text {loss }}(\mathrm{mm})$, that is the difference between $h_{\text {tot }}$ and total net runoff volume, maximum rainfall intensity $P_{\max }(\mathrm{mm} / \mathrm{hr})$ and total event duration $T$ with rainfall intensity $P>0$.

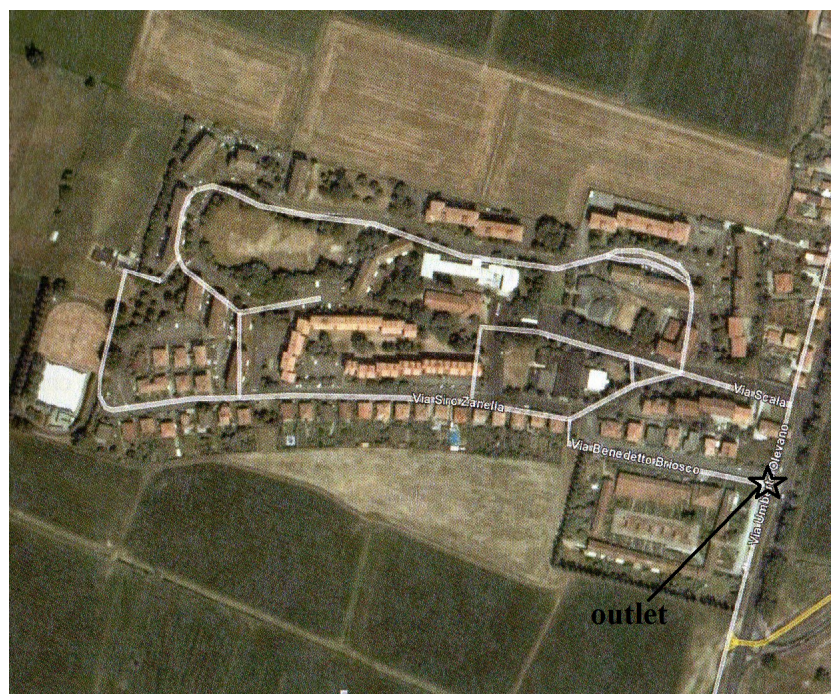

Figure 1: Aerial view of the Cascina Scala quarter, adapted from (Papiri, Ciaponi, \& Todeschini, 2008)

\section{Hydrological model}

The event Hydrological model set up in this work enables transformation from total to excess rainfall (subsection 3.1) and from excess rainfall to runoff at catchment outlet (subsection 0). Therefore, starting from total hyetograph in a generic rain event (model input), the model reconstructs the hydrograph at the outlet (model output). The parameterization is described in subsection 3.3.

\subsection{Determination of the excess rainfall}

Given a certain rainfall event with hyetograph $P_{t o t}(t)$, the excess rainfall hyetograph $P_{\text {excess }}(t)$ is determined by applying the deficit and constant method (Figure 2) (Feldman, 2000). After the total water loss volume $h_{\text {loss }}(\mathrm{mm})$ has been set, as the product of the loss coefficient $C(-)$ and the total rainfall volume $h_{\text {tot }}(\mathrm{mm})$ (i.e. $h_{\text {loss }}=C \cdot h_{t o t}$ ), this method allocates a certain fraction $r(-)$ to the initial part of the hyetograph (deficit or initial abstraction), which is totally consumed by the loss. This entails that the initial water loss coincides with $P_{t o t}(t)$ for time $t(\mathrm{hr})$, this latter ranging from 0 to a certain instant $t_{1}(\mathrm{hr})$. The remaining water loss volume fraction (1-r), instead, is allocated with the $\phi$-constant method (Feldman, 2000), that is with a constant rate $(\mathrm{mm} / \mathrm{hr})$ up to the end of the rain event, i.e. time instant $T(\mathrm{hr})$. 


\begin{tabular}{|c|c|c|c|c|c|c|c|c|c|c|}
\hline ID & date & $\begin{array}{c}h_{\text {tot }} \\
(\mathbf{m m})\end{array}$ & $\begin{array}{c}h_{\text {loss }} \\
(\mathbf{m m})\end{array}$ & $\begin{array}{c}P_{\max } \\
(\mathbf{m m} / \mathbf{h r})\end{array}$ & $\begin{array}{c}T \\
(\mathbf{h r})\end{array}$ & $C(-)$ & $r(-)$ & $n(-)$ & $k(\mathrm{hr})$ & $R^{2}$ \\
\hline 1 & $15 / 06 / 1990$ & 7.80 & 5.37 & 51 & 1.55 & 0.31 & 0.94 & 3.27 & 0.055 & 0.96 \\
\hline 2 & 07/09/1990 & 15.20 & 10.68 & 140 & 0.57 & 0.30 & 0.61 & 7.45 & 0.035 & 0.96 \\
\hline 3 & 01/06/1992 & 5.78 & 3.22 & 76 & 0.27 & 0.44 & 0.92 & 1.66 & 0.109 & 0.99 \\
\hline 4 & 02/10/1992 & 38.58 & 21.84 & 89 & 2.53 & 0.43 & 0.00 & 1.07 & 0.464 & 0.77 \\
\hline 5 & $17 / 07 / 1997$ & 36.60 & 22.00 & 144 & 1.07 & 0.40 & 0.09 & 1.24 & 0.200 & 0.99 \\
\hline 6 & $15 / 06 / 1999$ & 12.77 & 9.23 & 13 & 4.88 & 0.28 & 0.04 & 1.10 & 0.235 & 0.93 \\
\hline 7 & $12 / 08 / 1999$ & 27.30 & 18.05 & 59 & 6.68 & 0.34 & 0.29 & 0.55 & 0.713 & 0.96 \\
\hline 8 & $10 / 06 / 2000$ & 12.79 & 6.87 & 137 & 0.18 & 0.46 & 0.49 & 7.43 & 0.024 & 0.97 \\
\hline 9 & $11 / 06 / 2000$ & 11.84 & 7.51 & 43 & 3.27 & 0.37 & 0.33 & 0.77 & 0.433 & 0.95 \\
\hline 10 & $17 / 03 / 2001$ & 26.21 & 13.73 & 24 & 7.97 & 0.48 & 0.12 & 0.72 & 0.630 & 0.94 \\
\hline 11 & $10 / 04 / 2001$ & 8.39 & 4.48 & 13 & 1.83 & 0.47 & 0.42 & 3.39 & 0.069 & 0.98 \\
\hline 12 & $23 / 06 / 2000$ & 16.39 & 9.66 & 76 & 1.80 & 0.41 & 0.54 & 2.34 & 0.070 & 0.91 \\
\hline 13 & $10 / 07 / 2000$ & 10.99 & 6.98 & 54 & 1.07 & 0.37 & 0.53 & 3.57 & 0.060 & 0.97 \\
\hline 14 & $11 / 07 / 2000$ & 10.61 & 8.38 & 19 & 3.58 & 0.21 & 0.12 & 2.13 & 0.108 & 0.95 \\
\hline 15 & $28 / 03 / 2001$ & 5.38 & 2.80 & 24 & 1.55 & 0.48 & 0.64 & 1.97 & 0.128 & 0.98 \\
\hline 16 & $28 / 03 / 2001$ & 5.80 & 2.64 & 55 & 0.50 & 0.54 & 0.34 & 2.23 & 0.114 & 0.98 \\
\hline 17 & $27 / 08 / 1989$ & 14.20 & 10.39 & 119 & 0.28 & I & I & I & I & / \\
\hline 18 & $28 / 04 / 1993$ & 16.20 & 8.34 & 46 & 2.52 & I & I & I & I & 1 \\
\hline 19 & $27 / 08 / 1993$ & 8.38 & 5.30 & 45 & 0.48 & I & I & I & I & / \\
\hline 20 & 19/06/1994 & 14.42 & 9.27 & 99 & 1.58 & I & I & I & 1 & / \\
\hline 21 & $14 / 09 / 1994$ & 21.20 & 13.96 & 154 & 0.60 & I & I & I & I & / \\
\hline 22 & 04/06/1995 & 7.25 & 5.26 & 90 & 0.38 & I & I & I & 1 & / \\
\hline 23 & 03/05/1996 & 5.37 & 3.00 & 37 & 0.42 & I & 1 & 1 & 1 & / \\
\hline 24 & 28/08/1996 & 10.85 & 7.19 & 49 & 1.03 & I & I & / & 1 & / \\
\hline 25 & $16 / 06 / 1997$ & 10.56 & 6.26 & 30 & 0.87 & 1 & I & I & I & / \\
\hline 26 & $30 / 06 / 1998$ & 7.39 & 5.18 & 81 & 0.35 & I & I & I & 1 & / \\
\hline 27 & $14 / 07 / 1998$ & 15.00 & 10.27 & 85 & 1.15 & l & I & / & I & / \\
\hline 28 & $11 / 06 / 2000$ & 19.30 & 10.40 & 159 & 1.68 & I & I & I & 1 & / \\
\hline 29 & $28 / 06 / 2000$ & 15.58 & 8.86 & 206 & 0.37 & I & I & I & I & 1 \\
\hline 30 & $11 / 06 / 2000$ & 15.06 & 9.46 & 73 & 3.70 & I & I & I & I & / \\
\hline 31 & $20 / 04 / 2001$ & 10.83 & 4.98 & 39 & 3.10 & I & I & I & I & 1 \\
\hline 32 & $12 / 08 / 1999$ & 21.18 & 13.45 & 19 & 7.32 & 1 & 1 & 1 & 1 & 1 \\
\hline
\end{tabular}

Table 1: Main characteristics of the rain events monitored in the Cascina Scala catchment, in terms of event ID, date, $h_{\text {tot }}, h_{\text {loss }}, P_{\max }$ and duration $T$. As for the model parameterized on the single event (step 1 in parameterization approach 1), values of parameters $C, r, n$, and $k$, and model fit in terms of $R^{2}$. 


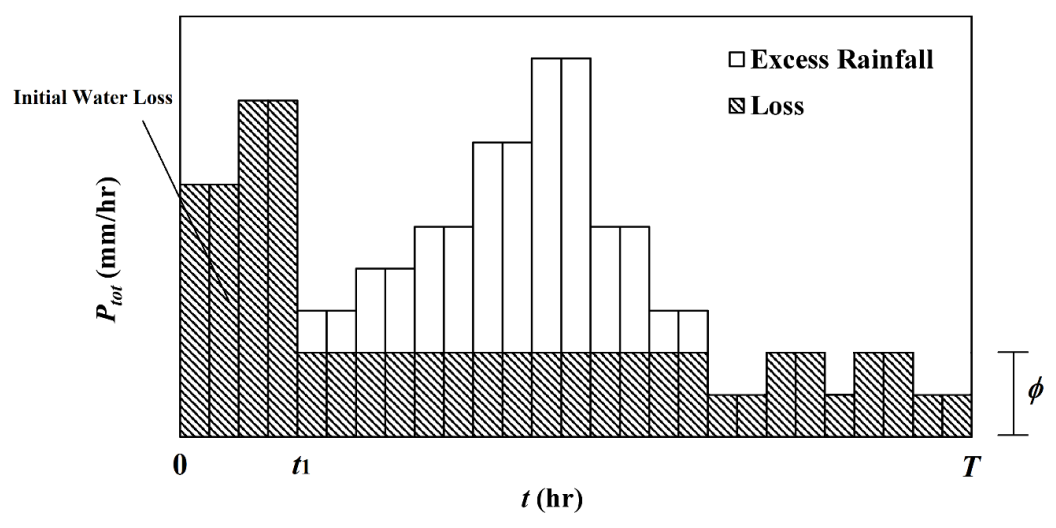

Figure 2: Representation of the deficit and constant method (Feldman, 2000)

At the generic time instant $t$ following $t_{1}$, the loss intensity will be equal to $\phi$, if the total instantaneous intensity $P_{t o t}(t)$ is larger than or equal to $\phi$. Otherwise, it is equal to the rainfall intensity $P_{\text {too }}(t)$. It must be noted that the deficit and constant method mimics the decreasing trend of the infiltration capacity as a function of time that would be obtained in more complete models, such as the Horton (Horton, 1933) and Green-Ampt (Green \& Ampt, 1911) infiltration models.

\subsection{Flow routing}

A model based on the IUH concept (Chow, Maidment, \& Mays, 1988), that is the Nash Cascade of reservoirs (Nash, 1957), was considered for simulating the flow routing and thus for calculating, for each event, the hydrograph at the outlet of the catchment. The flow routing has two parameters: number $n(-)$ of linear reservoirs and storage coefficient $k(\mathrm{hr})$.

\subsection{Parameterization}

The hydrological model described in subsections 3.1 and 0 features four parameters: $C$ and $r$, related to excess rainfall determination, and $n$ and $k$, related to flow routing. $C$ was simply assessed through the ratio of measured hydrograph to hyetograph volume. A genetic algorithm (Mitchell, 1996) was set up to search for the other parameter values that maximize the fit of simulated water discharges to calculated water discharges. To this end, the following objective function $f$ was minimized:

$$
f=\sum_{i=1}^{N}\left(Q_{c a l c, i}-Q_{m e a s, i}\right)^{2}
$$

where $Q_{c a l c, i}$ and $Q_{\text {meas }, i}$ are the calculated and measured water discharges at the $i$-th of the $N$ time instants considered.

Two different parameterization approaches were used to estimate the model parameters in a group of rain events: parameterization approach 1 and parameterization approach 2 . The former is based on two steps: 1) estimation of the optimal set of parameters in each rainfall event through minimization of the objective function in Eq. (1), with $N$ representing the number of time instants in the generic event; 2) calculation of the ultimate set of parameters for the whole group of events by averaging the values obtained in step 1 . The latter approach, instead, attempts to minimize the objective function in Eq. (1) in the whole group of events at the same time. To this end, the sum in Eq. (1) must be 
extended to a number $N$ of time instants equal to the sum of the time instants of the various events in the group. This confers a larger computational overhead on parameterization approach 2 .

The models obtained with parameterization approaches 1 and 2 are indicated as models 1 and 2, respectively.

\section{Results}

For applying and analysing the parameterization approaches, the 32 monitored events were divided into two groups, i.e. calibration group and validation group, comprising the events 1-16 and the events 17-32 in Table 1, respectively.

The first step of parameterization approach 1 required minimization of the objective function in Eq. (1) for each event in the calibration group. The optimal set of parameters and the $R^{2}$ value obtained are reported in Table 1. The fact that all but one of the $R^{2}$ values are larger than 0.9 attests to the capability of the model to represent properly the hydrological response of the catchment. Then, according to the second step of parameterization approach 1, the averaging of the parameters over the whole calibration group led to the following values: $C=0.61, r=0.40, n=2.56$ and $k=0.22 \mathrm{hr}$.

The application of parameterization approach 2 consisted in the minimization of the objective function in Eq. (1) in all the events of the calibration group at the same time. This led to the following set of parameters: $C=0.61, r=0.25, n=1.30$ and $k=0.24 \mathrm{hr}$.

Models 1 and 2, which used the sets of parameters obtained in parameterization approaches 1 and 2 respectively, were applied to the 16 events of the calibration group and to the 16 events of the validation group.

As an example of the results in the calibration group, Figure 3 shows the hydrological response of models 1 (graph a) and 2 (graph b) to event 15. Graph b) proves that the trend of calculated water discharges $Q_{\text {calc }}$ in model 2 follows quite well the trend of measured water discharges $Q_{\text {meas }}$. Graph a) shows that the response of model 1 is much worse, due to the poor identification of the peak water discharge. As for the fit of $Q_{\text {calc }}$ to $Q_{\text {meas }}$, the $R^{2}$ values of models 1 and 2 are 0.11 and 0.94 , respectively.
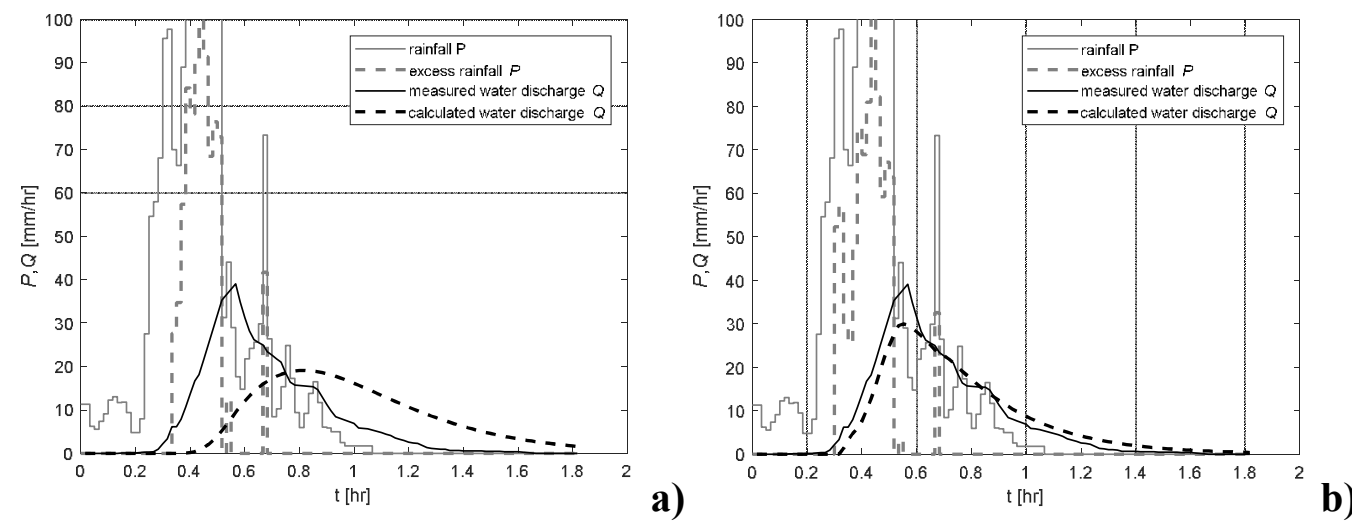

Figure 3: Application of model 1 (a) and 2 (b) to rain event 15. Rainfall $P_{\text {tot }}$, Excess rainfall $P_{\text {excess, }}$ measured net water discharge $Q_{\text {meas }}$ and calculated net water discharge $Q$

As an example of the results in the validation group, Figure 4 shows the hydrological response of models 1 and 2 to event 20, leading to similar remarks to event 15 . In this case, the $R^{2}$ values of models 1 and 2 are 0.29 and 0.87 , respectively. 

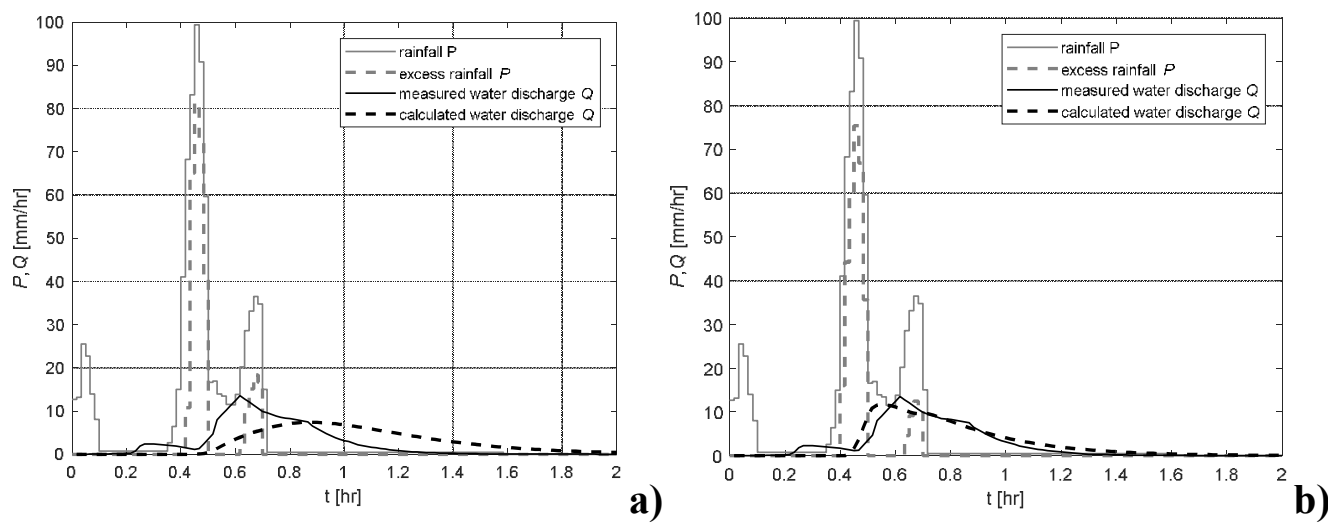

Figure 4: Application of model 1 (a) and 2 (b) to rain event 20. Rainfall $P_{\text {tot }}$, Excess rainfall $P_{\text {excess, }}$ measured net water discharge $Q_{\text {meas }}$ and calculated net water discharge $Q$

The graphs in Figure 5 show the comparison of the $R^{2}$ values obtained with models 1 and 2. Graph a) shows the $R^{2}$ values obtained with model 2 plotted against those obtained with model 1 , highlighting that the former values are higher than the latter in almost all the events. Graph b) shows, instead, the Weibull cumulative frequency $F\left(R^{2}\right)$ for models 1 and 2, considering the calibration and validation events. This graph highlights that the cumulative frequency curves obtained with model 2 lie abundantly to the right of those obtained with model 1 , confirming the better performance of the former. Another merit of model 2 is that it has no performance decay when moving from the calibration to the validation phase.
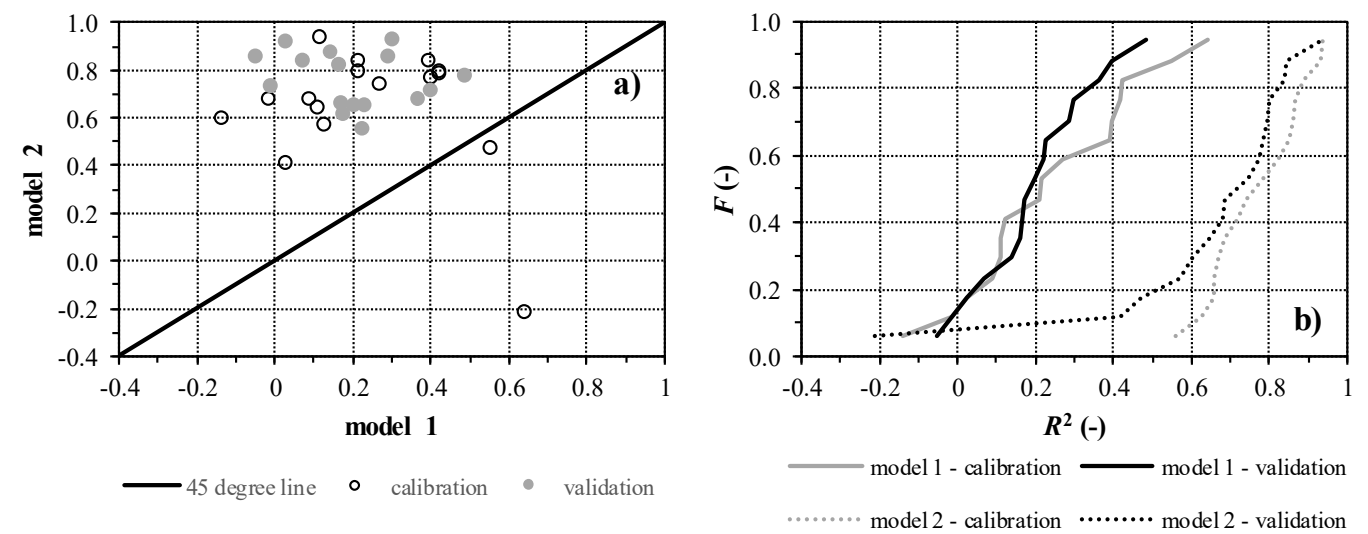

Figure 5: Comparison of models 1 and 2 in terms of $R^{2}$ in the calibration and validation events; b) Weibull cumulative frequency $F\left(R^{2}\right)$ for models 1 and 2, considering the calibration and validation events

As for the effectiveness of model 2, Figure 6 shows that, in many events of the calibration group, the $R^{2}$ values obtained through model 2 are almost as high as the highest $R^{2}$ values obtainable in each rain event through single event parameterization (i.e. after step 1 in parameterization approach 1 ). However, the parameterization on the single event leads to a hydrological model with very variable parameter values (see Table 1), which represents the effects of both the physics and the noises 
inherent in the rainfall-runoff transformation. Parameterization approach 2, instead, leads to a hydrological model with a single set of parameters, which is expected to catch only the effects of the physics in the rainfall-runoff transformation.

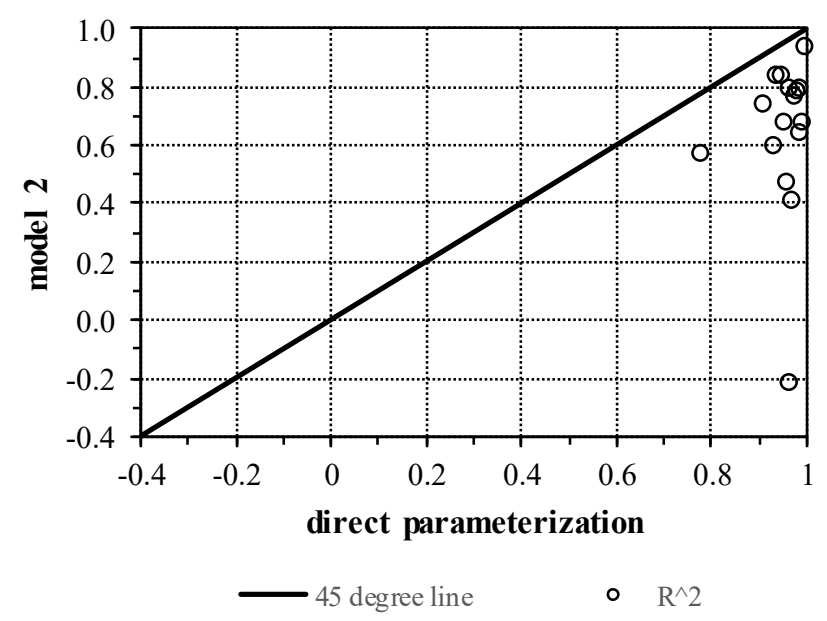

Figure 6: Comparison of model 1 - step 1 and model 2 in terms of $R^{2}$ in the calibration events

\section{Conclusions}

This work reported some results of the hydrological modelling of the Cascina Scala catchment. The hydrological response of this catchment during rain events was simulated through a model based on the deficit and constant method and on the Nash cascade of reservoirs, for excess rainfall determination and for flow routing respectively. The model parameters were estimated using two different approaches, based on averaging the optimal parameter values obtained in various rain events and on optimizing the model parameters over the whole group of rain events at the same time, respectively. The applications of this work proved the superiority of the latter in reproducing the measured hydrographs at the catchment outlet. This entails that, though being more cumbersome from the computational viewpoint, optimizing model parameters over a whole group of events at the same time enables obtaining a more consistent hydrological model, which better reproduces the hydrological response of the catchment.

Future work will be dedicated to comparing the results of the models developed in this paper with those of more complete models, in which the hydraulic simulation of culverts complements the hydrologic representation of catchment external surfaces.

\section{References}

Alvisi, S., Creaco, E., \& Franchini, M. (2012). Crisp discharge forecasts and grey uncertainty bands using data-driven models. Hydrology Research, 43(5), 589-601. Retrieved from Templates for proceedings.

Boufadel, M. (1998). Unit Hydrographs Derived from the Nash Model. Journal of the American Water Resources Association, 34(1), 167-177. 
Box, G., \& Jenkins, G. (1970). Time Series Analysis: Forecasting and Control. Oakland(CA): Holden-Day.

Chen, J., \& Adams, B. (2006). Integration of artificial neural networks with conceptual models in rainfall-runoff modeling. Journal of Hydrology, 318(1-4), 232-249.

Chow, V., Maidment, D., \& Mays, L. (1988). Applied Hydrology. New York: McGraw-Hill.

Dawdy, D., \& O'Donnel, T. (1965). Mathematical models of catchment behaviour. Journal of the Hydraulics Division, 91(4), 123-137.

Dooge, J. (1977). Problems and methods of rainfall-runoff modeling. In T. M. Ciriani, Mathematical Models for Surface Water Hydrology: the Workshop Held at the IBM Scientific Center (pp. 71-108). New York(NY): John Wiley \& Sons.

Feldman, A. (2000). Hydrologic Modeling System HEC-HMS. Technical Reference Manual. Washington(DC): US Army Corps of Engineers, Hydrologic Engineering Center HEC.

Ford, D., \& Hamilton, D. (1996). Computer models for water-excess management. (L. W. Mays, Ed.) New York: McGraw-Hill.

Green, W., \& Ampt, G. (1911). Studies of soil physics, part I - the flow of air and water through soils. J. Ag. Sci., 4(1), 1-24.

Horton, R. (1933). The role of infiltration in the hydrologic cycle. Trans. Am. Geophys. Union, 446460.

Kim, S. (2000). The Long-term Inflow Analysis of Multipurpose Reservoirs by the SEAMOD. KSCE Journal of Civil Engineering, 4(2), 91-101.

Londhe, S., \& Charhate, S. (2010). Comparison of data-driven modelling techniques for river flow forecasting. Hydrological Sciences Journal, 55(7), 1163-1174.

Mitchell, M. (1996). An Introduction to Genetic Algorithms. Cambridge(MA): MIT Press.

Nash, J. E. (1957). The form of the instantaneous unit hydrograph. IASH publication, 45, 114-121.

Nayak, P., Venkatesh, B., \& Krishna, B. (2013). Rainfall-runoff modeling using conceptual, data driven, and wavelet based computing approach. Journal of Hydrology, 493(17), 57-67.

Özger, M. (2009). Comparison of fuzzy inference systems for streamflow prediction. Hydrological Sciences Journal, 54(2), 261-273.

Panu, V., \& Unny, T. (1980). Extension and application of feature prediction model for synthesis of hydrologic records. Water Resources Research, 16(1), 77-96.

Papiri, S., Ciaponi, C., \& Todeschini, S. (2008). Il bacino urbano sperimentale di Cascina Scala (Pavia). Roma: Aracne Editrice S.r.l.

Rezaie-Balf, M., \& Kisi, O. (2017). New formulation for forecasting streamflow: evolutionary polynomial regression vs. extreme learning machine. Hydrology Research. doi:10.2166/nh.2017.283

Roy-Poirier, A., Filion, Y., \& Champagne, P. (2015). An event-based hydrologic simulation model for bioretention systems. Water Science and Technology, 72(9), 1524-1533.

Salas, J., Tarawneh, Z., \& Biondi, F. (2012). A hydrological record extension model for reconstructing streamflows from tree-ring chronologies. Hydrological Processes, 29, 544556.

Singh, V. (1995). Watershed Modeling. In V. Singh, Computer Models of Watershed Hydrology (pp. 1-22). Littleton(CO): Water Resources Publications.

Todeschini, S. (2016). Hydrologic and environmental impacts of imperviousness in an industrial catchment of Northern Italy. Journal of Hydrologic Engineering, 21(7), 05016013.

Todini, E. (1988). Rainfall-runoff modeling - Past, present and future. Journal of Hydrology, 100(13), 341-352.

Valencia, R., \& Schaake, J. (1973). Disaggregation processes in stochastic hydrology. Water Resources Research, 9(3), 580-585. 